\title{
ON THE RELATION BETWEEN SIZE AND PHOTOCHEMICAL ACTIVITY OF FRAGMENTS OF SPINACH GRANA \\ by
}

\author{
J. B. THOMAS*, O. H. BLAAUW AND L. N. M. DUYSENS* \\ Biophysical Research Group Utrecht/Delft under the direction of A.J. Kluyver, Delft, \\ and J.M.W. Milatz, Utrecht (Netherlands)
}

\section{INTRODUCTION}

Concerning the occurrence of the photosynthetic unit many discussions have been published. Nevertheless, the interpretations of the results as well as the assumptions on which the theories are based yield no definite proof as to presence or absence of such a unit. In fact, things have become complicated to such a degree that we are now in want of a new definition of the photosynthetic unit.

With this in mind we may state that the following study has been started from the original observation of EMERSON AND ARNOLD ${ }^{1}$ who established that, in flashing light experiments with Chlorella, maximally one carbon dioxide molecule was reduced per about 2500 chlorophyll molecules present. We quote: "The total chlorophyll content of the sample, divided by the number of carbon dioxide molecules reduced per flash will give the number of chlorophyll molecules per unit, or per molecule of carbon dioxide", and: "We define one unit arbitrarily as the mechanism which must undergo the photochemical reaction to reduce one molecule of carbon dioxide".

ARNOLD AND KOHN ${ }^{2}$ obtained nearly the same ratio with six plant species. So Chlorella proved to be no exception in this respect.

However, EMERSON, GREEN AND WEBB ${ }^{3}$ stated that the number of moles of chlorophyll per mole of carbon dioxide reduced per flash in Chlorella increases considerably with age of the cultures and varies with colour and light condition of the cells. They concluded: "Thus the maximum amount of carbon dioxide reducible per flash is not directly related to the amount of chlorophyll, but depends on some other internal factor."

As to this we may remark that, e.g. chlorophyll may occur in excess of the quantity of this pigment active in a unit. Since, with age, the chlorophyll concentration possibly may increase to a higher rate than the carbon dioxide reduction centres do, the statement of the latter authors does not exclude that the ratio of "active" chlorophyll molecules to carbon dioxide molecules reduced per flash is a constant.

It seemed worthwhile to try to establish the relation between the size of chlorophyll containing fragments of grana and their photochemical activity. This paper deals with the results of such a study. However, in disintegrated cells no complete photosynthesis has been observed with certainty. Recently VISHNIAC AND OCHOA as well as TOLMACH ${ }^{5}, 0$

* This investigation has been made possible by a grant of the Netherlands Organization for Pure Research (Z.W.O.).

References p. 240 . 
succeeded in demonstrating malate and lactate synthesis, coupled with carbon dioxide uptake, in illuminated chloroplast suspensions. We will leave out of consideration these highly interesting results here, since-as the authors stated-the reactions observed may differ considerably from those occurring in "normal" photosynthesis.

From the decrease of the oxido-reduction potential in illuminated chloroplast suspensions after supply of carbon dioxide GerRetsen ${ }^{7}$ concluded that this gas may be taken up here, be it to a far less degree-2 to $3 \%$ - than in photosynthesis.

So, in our experiments we used the oxygen liberation in the HiLL reaction as a measure for the photochemical activity, in contradistinction to EMERSON AND ARNOLD 1 who studied the carbon dioxide uptake in photosynthesis. Thus it may be remarked here that the unit definition of EMERSON AND ARNOLD ${ }^{1}$ is based on experiments concerning other reduction processes than those investigated by us.

As to the literature regarding the HILL reaction we restrict ourselves in citing recent reviews, such as FrenCH ${ }^{8}$, Holt AND FRENCH ${ }^{9}$, GAFFron AND FAGER ${ }^{10}$, and HiLl ${ }^{11}$.

\section{METHODS}

Preparation of the grana suspensions. After addition of about an equal volume of cooled $-0^{\circ} \mathrm{C}-$ tapwater, washed fresh leaves of Spinacia oleracea $\mathrm{L}$. were minced in a precooled Waring blendor for I minute. Then the brei was filtered rapidly through cotton wool and centrifuged in a precooled tube at about 1200 times $g$ for 5 minutes. The precipitated fraction, consisting of cell debris was discarded and the supernatant was divided into two portions. One of them served as a control whilst the second aliquot was used for disintegration. Next, oxygen was removed from both suspensions by maintaining a flow of pure nitrogen through the suspensions for 15 minutes. Then the containers were closed.

As much care as possible was taken in order to keep both samples under the same conditions. They were both kept stored over ice in darkness during the transport to the disintegrator and vice versa. During the disintegration - which procedure also occurred in darkness - the control portion was also removed from the ice, and allowed to stand at room temperature.

Depending on the experimental requirements the disintegrated suspensions were used as such, or they were submitted to fractional centrifugation in an angle-headed centrifuge which was placed in a refrigerator.

Next, the chlorophyll concentration of both samples was determined according to the method used by WARBURG AND LÜTTGENS ${ }^{12}$ by measuring the extinction of chlorophyll extracts from the suspensions by methanol at $578 \mathrm{~m} \mu$. Our thanks are due to $\mathrm{Mr} \mathrm{J}$. G. Komen for carrying out many of these measurements.

Now the control sample was adequately diluted to the same chlorophyll concentration as that of the disintegrated one. Then, the suspensions were made anaerobic as described above. Next, the reaction vessels were filled with $5.25 \mathrm{ml}$ of the samples, $\times .75 \mathrm{ml}$ phosphate buffer of $\mathrm{pH} 6.5$ and potassium chloride-ultimate concentrations $M / 20$ and $0.05 \%$ respectively-, and $0.2 \mathrm{ml}$ of a $\mathrm{I} \%$ quinone solution in $N /$ roo sulphuric acid-ct. WARBURG AND LÜTTGEN ${ }^{12}-$. Now the vessels were loosely adjusted to the manometers in order to enable the passing of a flow of nitrogen-for $\mathrm{I}_{5}$ minutes-through the manometer systems. Finally the vessels were fixed, the stopcocks closed, and the manometers mounted in the thermostat. Care was taken that the light absorption of the suspensions in the vessels was equal; it amounted to about $60 \%$ in sodium light.

We are much indebted to Prof. Dr V. J. KonINGSBERGER for enabling us to obtain fresh spinach leaves from the Botanical Gardens at Utrecht.

Disintegration procedure. Fragmentation of the grana occurred by means of a magnetostriction oscillator at a frequency of $7000 \mathrm{~Hz}$. The energy delivered to the magnetostrictive tube was about 300 watts. Approximately Io $\%$ of the energy was effective. The oscillator cup-diameter: $3 \mathrm{~cm}-$ was filled with the grana suspension to a height of $3 \mathrm{~cm}$. The diameter of the vibrating nickel tube amounted to $8 \mathrm{~mm}$. During operation a cooling spiral kept the cup at $12^{\circ} \mathrm{C}$. By the courtesy of Dr J. A. Niemeyer these experiments could be carried out with the oscillator of the Laboratory for Physiological Chemistry at Utrecht.

Measurement of the photochemical activity. The photochemical activity was determined with the aid of the HILL reaction using quinone as a reagent according to WARBURG AND LürTGENS ${ }^{12}$. The quinone was freshly prepared and purified by steam distillation. It was stored in the refrigerator.

The oxygen liberation was determined in a differential manometer as shown in Fig. I. The

References p. 240. 
manometer body was mounted at an inclination of $30^{\circ}$ in order to enlarge the distance to be covered by the manometer fluid-BRODIE solution - at pressure variations. Instead of by shaking, gas exchange in the vertically adjusted vessels was ensured by electromagnetic stirring after a slightly

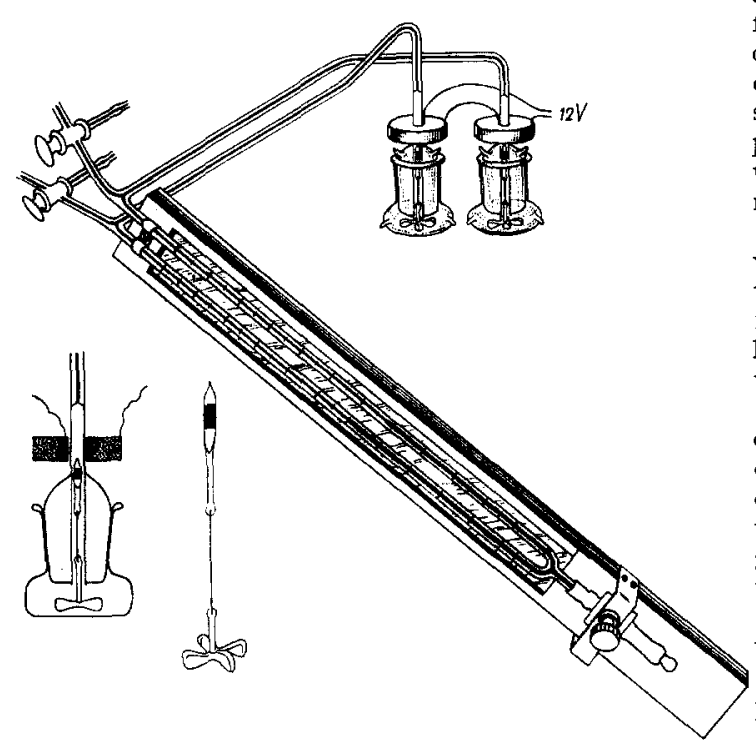

Fig. ז. Differential manometer, longitudinal section of a manometer vessel, and stirrer as used in the gas exchange measurements. Explanation see text. altered device of $\mathrm{KoK}^{13}$. The solenoids were fed with a periodically interrupted direct current of $\mathrm{I}_{2} \mathrm{~V}$. The stirrers moved up and down about 360 times per minute. They consisted of a glass "propellor", a middle part of platinum wire, and an upper one of glass containing an iron core. In this way stirring did not need to be interrupted during the readings.

The control vessel contained an equal volume of liquid as the experimental one. The temperature of the thermostat amounted to I6. $5^{\circ} \mathrm{C}$. In some experiments a somewhat higher temperature-up to $17.5^{\circ} \mathrm{C}$-was used.

The vessel constants were determined experimentally by evolving a known quantity of oxygen by a potassium permanganate-hydrogen peroxide reaction. The reliability of this method was checked by determining oxygen evolution of identical suspensions in both vessels.

Two manometer sets were used simultaneously. One of them contained the disintegrated solution, whilst the other one was provided with the non-treated grana.

As a light source a Philips sodium lamp was used. By means of diaphragms the vessels received merely direct light from an equal region of the radiation tube. By means of neutral glass filters-Schott $\mathrm{NG} \mathrm{3}_{3}, 4,5,6,8$ - the intensity of the incident light could be varied.

Measurement of the particle size. Preparations for the electron microscope were made from both samples. This was done in two ways: $r$. a little droplet of the suspensions was mounted on the collodion film of the object bearer, and, after evaporation of the water, the preparation was "washed" by gently blowing about $0.5 \mathrm{ml}$ distilled water out of a micropipette, and: 2 . the suspensions were adequately diluted with distilled water, and a little droplet was mounted without "washing" afterwards.

The preparations were shadowed with a gold-manganin mixture-I: 1 -at an angle of $I: 4.5$ The pictures were taken at a magnification of $2500 \times$ on the registering film-Ilford direct electron recording film $5 \mathrm{BrI}$ - at $80 \mathrm{kV}$. An optical after-magnification of ${ }_{3}$ times was used. So, I $\mu$ corresponded with $32.5 \mathrm{~mm}$.

The diameter of all particles occurring per $\mu^{2}$ was measured with the aid of a millimeter scale. With each preparation this procedure was repeated 2 to 6 -mostly 3-times at different spots of the micrograph. The measurements yielded frequency curves per diameter interval of $1.0 \mathrm{~mm}$, which coincided rather well within each experiment. The mean frequency curve was used for further analysis. From this one a second graph of the total volume per diameter interval as a function of the diameter was derived. Particles with a diameter smaller than zo $\mathrm{m} \mu$ were considered to be spherical.

\section{INFORMATIVE EXPERIMENTS}

With regard to the validity of our conclusions a study of some requirements, which must be satisfied, was needed. A brief account of these experiments may follow here. Linearity of the relation between light intensity and oxygen evolution by a grana suspension in weak light. This linearity has already been established by HOLT AND FRENCH, and GoRHAM AND CLENDENNING ${ }^{14}$. However, it was necessary to check whether, with our material and under our experimental conditions, such a linearity occurred too. 
Since the oxygen evolution per unit of time of grana suspensions decreases with time, and, moreover, the rate of this decrease was found to depend on the intensity

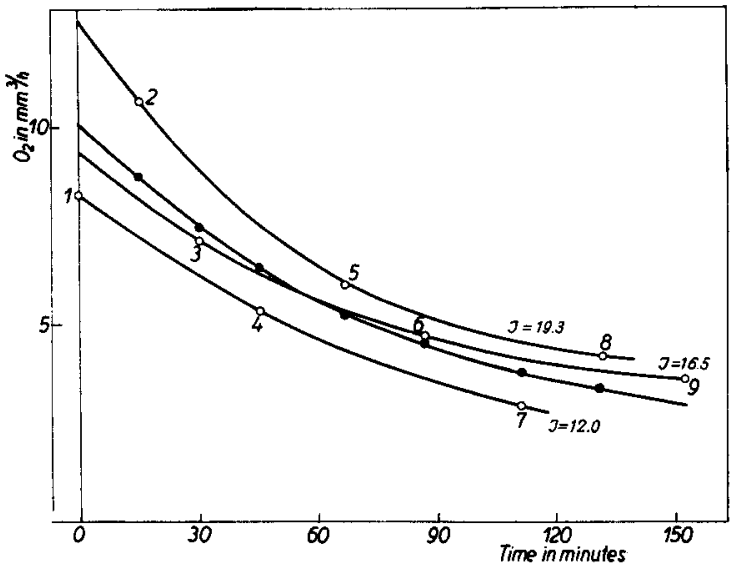

Fig. 2. Influence of ageing and light on the rate of the HILL reaction of a grana suspension. Open circles: measured values. Dark circles: means calculated from the three experimentally determined graphs. I in arbitrary units. The figures indicate the succession of the determinations of the points. dicated that, within the narrow range of these intensities, we may apply this simplification as a first approximation.

The results of this correction are shown in Fig. 3a. In Fig. $3 \mathrm{~b}$ the means are plotted. They demonstrate that, under the above conditions of both material and experiments, oxygen evolution by the suspension is an approximately linear function of light intensity.

Checking of harmful effects resulting from the supersonic treatment. When disintegrated in the presence of air, the grana suspension lost about $30 \%$ of its photochemical activity at a vibration period of half a minute. By doubling this period the activity was totally lost. If, however, air was replaced by purified nitrogen, a one minute supersonic treatment reduced the activity only about $5 \%$.

This proves that the activity loss in air is due to oxidation-PRUDHOMME AND GRABAR $^{15}$ - rather than to increase of temperature-DogNON AND SIMONDT ${ }^{16}$-.

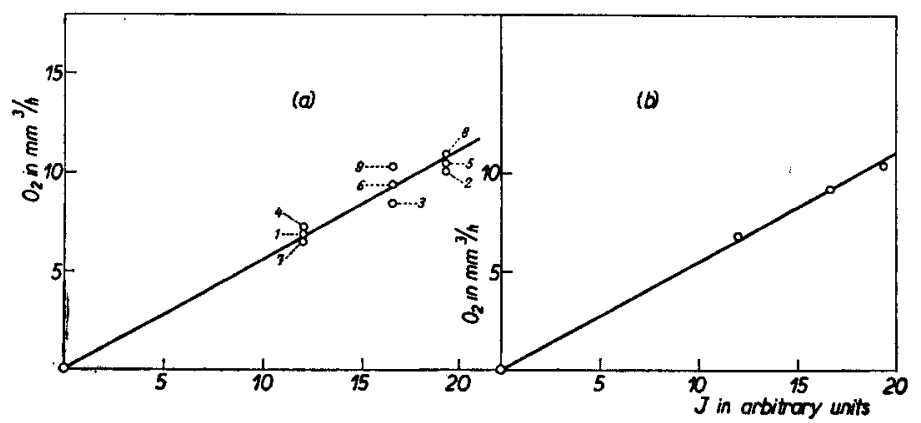

Fig. 3. Evidence of a linear relation between oxygen evolution by a grana suspension and weak light intensities. a: readings corrected with time factor derived from Fig. 2. b: means of the values from Fig. 3 a. Figs. 2 and 3 represent the same experiment. 
Moreover, it may be stated that, although-relatively weak-cavitation occurred, no luminescence was observed-PRUDHOMME ${ }^{17}$. However, the decrease of activity under anaerobic vibration conditions might be due to oxidation by traces of oxygen present in the nitrogen or by oxygen molecules adhering to suspension particles and to the walls of the cup. This possibility was studied as follows. A grana suspension was divided into two portions as usually. One of them was vibrated in purified nitrogen for 16 minutes, then one half of it was removed from the vibration cup by blowing it out with the aid of nitrogen. This portion (a) was stored in the refrigerator. The remaining portion $(b)$ was supersonically treated for 16 minutes once more. Next, it was placed in the refrigerator. The vibration cup was cleaned and dried, then filled with portion $(a)$, and the procedure to remove air was repeated in the usual way. Next, this portion $(a)$ was submitted to supersonic vibration for I6 minutes. Finally the HrLl activity of the control as well as of the portions $(a)$ and $(b)$ was determined. In this way the total duration of the disintegration period of both portions $(a)$ and $(b)$ was equal. However, effects of eventual traces of oxygen will occur twice in portion $(a)$ and only once in portion $(b)$. In fact the activity of both $(a)$ and $(b)$ amounted to three per cent of that of the control. This may indicate that oxidation effects due to remaining traces of oxygen were absent.

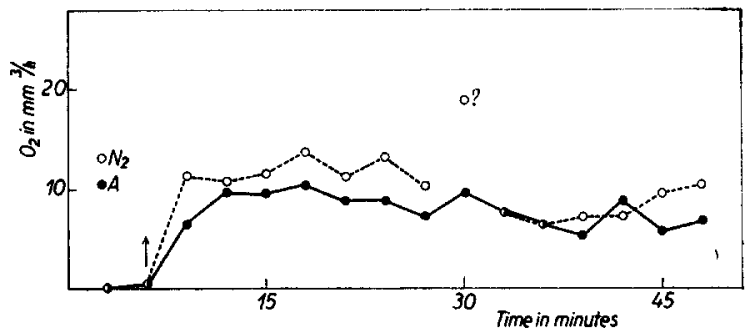

Fig. 4. Oxygen evolution of a grana suspension under argon-open circles-and under nitrogen - dark circles. The arrow indicates turning on of the light.

We further investigated whether harmful nitrogen effects occurred during vibration. This was done by comparing the photochemical activity of two portions of the same suspension, one of which was treated as usually, whilst in the other one nitrogen was replaced by argon - Philips, spectrically pure. Both samples were supersonically treated for 6 minutes. Fig. 4 shows that no significant difference of the rates of oxygen evolution in both suspensions occurred.

Apart from the possible disturbances studied, there may be harmful vibration effects whatsoever. As to this we obtained information in the following way. Suspensions of grana fragments of the same mean size were prepared in two ways: r. by a supersonic treatment for 27 minutes followed by short-lastening centrifugation, and 2 . by removing "large" particles by repeated fractional centrifugation from a suspension which had been vibrated for ro minutes. The composition of the "long time vibrated" suspension is shown in Fig. 6 by graph $a$, that of the "short time vibrated" one by graph $b$. As it may be expected, the optimum of the latter one is narrower than that of graph $a$. The photochemical activity of both samples proved to be equal; in fact it amounted to about $20 \%$ for both the "long time vibrated" and the "short time vibrated" ones.

The above may demonstrate that the described supersonic technique is suitable for our purpose. MilneR, LAWRENCE AND FRENCH ${ }^{18}$ described a method to obtain dis- 
integrated chloroplasts by pressing them through a steel needle valve. In this way vibration effects do not enter into the picture. Since, however, the supersonic procedure enables the use of relatively large quantities, we preferred the latter procedure after checking its reliability.

Checking of the method for particle size measurement. The applied procedure is based on two postulates. $\mathrm{I}$. The fraction of chlorophyll-bearing particles present in the vibrated suspension is independent of the particle size. 2. This fraction remains the same at concentrating due to evaporation, or at diluting when mounted on the collodion film.

Since chlorophyll-bearing particles cannot be recognised as such under the electron microscope, we were not able to check the fulfilment of the first postulate in a direct way. As described previously we measured the diameter of all particles occurring in a square $\mu$. However, the single peaks of the distribution graphs of Fig. 6 suggest that this requirement is met.

In order to check whether the second postulate was fulfilled, electron microscopical preparations were made in the two described ways: either by mounting a droplet of the suspension and washing the residue after drying, or by diluting the suspension and mounting it without washing afterwards. In both cases the distribution of the particle size in the suspension was found to be the same. Moreover, the same results were obtained on measuring different particle concentrations. So it seems justified to conclude that both postulates are fulfilled.

Three remarks remain to be made. First, the accuracy of the measurement of particles with a diameter of about $3 \mathrm{~m} \mu$ is decreased by the fact that particles beyond the resolving power-about $2.5 \mathrm{~m} \mu$ - of the electron microscope may be seen as spots on the micrographs, and may be measured too. This means that the value of the smallest mean particle size may be determined somewhat too high.

Second, the determination of the size of relatively large particles-diameter surpassing $I_{5} \mathrm{~m} \mu$-is troubled by the fact that, when preparing such-like suspensions, centrifugation could not be rendered sufficiently selective without extending its duration too much with regard to the activity loss of the preparations. So, we applied a correction based on the following reasoning. The combined volume of the grana and the intact lamellae occurring per square $\mu$ was calculated as the percentage of the total volume of the material present in this area. This percentage $(a)$ may be considered to be fully active, in other words, to show activity I.0o, equal to that of the control. Now the activity $(A)$ of the remaining portion $(b)$, which we wanted to determine, can be computed from the observed HILL activity $\left(A_{\text {obs }}\right)$ according to the equation:

$$
A=\frac{A_{\mathrm{obs}}-a}{b}
$$

We are well aware that this calculation yields an approximation only. For, in this way, a presumably small fraction of minute particles originating from the colourless stroma are taken into account too. So we present the corrected activity of the weakly disintegrated suspension with some reserve.

The third remark concerns the occurrence of precipitates of soluble proteins in the electron microscopical preparations. They are formed during the evaporation of the suspension droplet. These particles originate after supersonic treatment. So, their mutual size relations will be found the same in both non-vibrated and vibrated suspensions. Especially in micrographs of highly disintegrated material these structures may become 
evident; in fact, the graphs representing the relation between number and diameter of the particles show a second weak optimum between about $\mathrm{I} 2$ and $30 \mathrm{~m} \mu$. Their number,

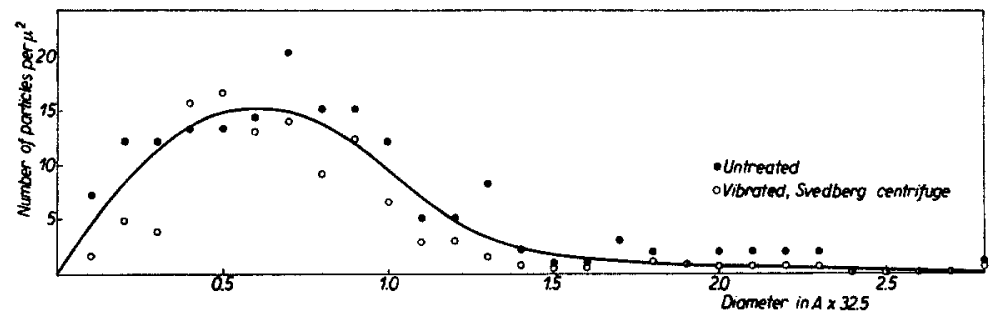

Fig. 5. Evidence of the occurring of particles unaffected by supersonic treatment. Open circles: particles formed during drying of a protein solution, obtained by centrifuging a vibrated grana suspension in the SveDBerg centrifuge. Black circles: particles occurring in non-vibrated control suspensions of grana.

however, is only a small fraction of that of the disintegrated particles. In order to check the above, a nearly chlorophyll-free clear solution of a weak yellow-greenish coluur - containing only soluble proteins - was prepared with the aid of a Svedberg ultracentrifuge. In this respect our thanks are due to Dr H. REERINK.

Electron microscopical preparations of this solution were made in the usual way. The results of the measurement of the particle diameter are shown by the open circles in Fig. 5. In the same figure the black circles denote means of analogous determinations at small particles of four non-vibrated grana suspensions. The location of the broad optimum of both graphs coincides rather well. This suggests that the above-mentioned particles are chlorophyll-free and, consequently, must be left out of consideration. So, the graphs represented in Fig. 6 are corrected in this respect.

\section{RESULTS}

The composition of the studied suspensions with regard to particle size is shown in Fig. 6. Here the

\section{TABLE I}

RELATION BETWEEN PHOTOCHEMICAL ACTIVITY AND PARTICLE SIZE

\begin{tabular}{ccc}
\hline Exp. No. & $\begin{array}{c}\text { Mean volume of } \\
\text { particles in } A^{8}\end{array}$ & Activity in \% \\
\hline & & \\
40 & $2.5 \cdot 10^{5}$ & 6 \\
39 & $3.8 \cdot 10^{5}$ & 17 \\
36 & $4.2 \cdot 10^{5}$ & 17 \\
38 & $4.2 \cdot 10^{5}$ & -5 \\
37 & $4.6 \cdot 10^{5}$ & 0 \\
35 & $5.1 \cdot 10^{5}$ & 37 \\
43 & $6.6 \cdot 10^{5}$ & 30 \\
42 & $9.0 \cdot 10^{5}$ & 44 \\
41 & $1.1 \cdot 10^{6}$ & 55 \\
45 & $1.3 \cdot 10^{7}$ & 66 \\
C & $7.1 \cdot 10^{9}$ & 100
\end{tabular}

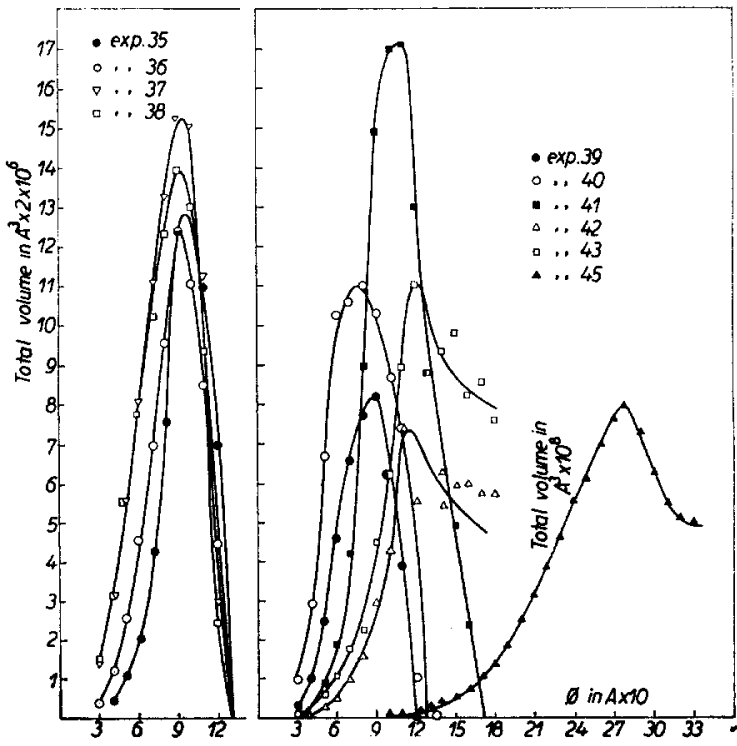

Fig. 6. Composition of the studied vibrated suspensions with regard to particle size.

$a=\exp .39 ; \quad b=\exp \cdot 3^{6}$. 
total volume of the grana fragments per diameter interval as a function of the diameter is plotted. From these graphs we derived the size of the particles which occupied the largest volume in each suspension. Together with the corresponding photochemical activities these sizes are represented in Table I.

These data are plotted in Fig. 7. It is evident that a rapid activity decrease occurs when the particle size is diminished below $10^{6} \mathrm{~A}^{3}$. The activity is lost in fragments smaller than about $2 \cdot 10^{5} \mathrm{~A}^{3}$.

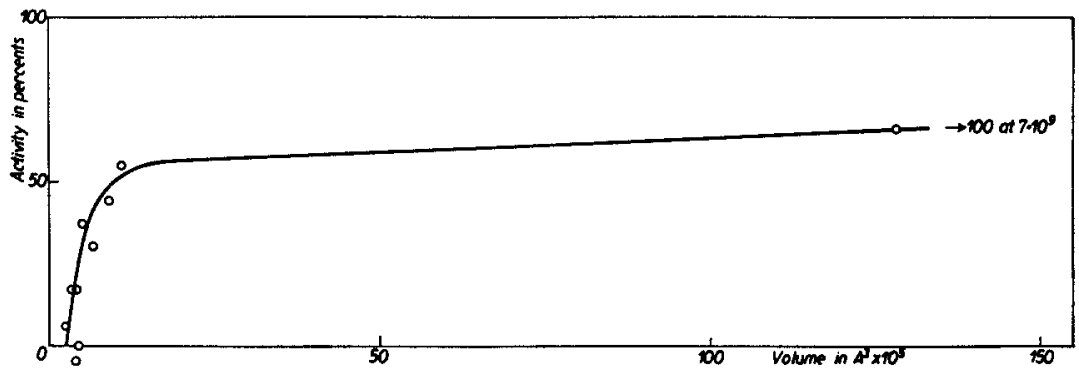

Fig. 7. Relation between oxygen evolution and particle size.

The observed activity decrease may be due to two causes. First, reduction of the fragment size below the critical volume $-10^{6} \mathrm{~A}^{3}$ - may cause a total activity loss of the particle. Second, diminishing of the particle size below the critical one only reduces the photochemical rate. Moreover both phenomena may occur simultaneously.

This problem can be solved by determining the activity percentage of a vibrated suspension at low light intensity - at which the oxygen evolution of both control and the disintegrated suspension depends on light intensity in a linear way - as well as at high intensity, in which in both samples light saturation occurs.

In these experiments a high power projection lamp-30 V, 900 watt, Philips E40with an infrared absorbing filter-Schott BGI7, $2 \mathrm{~mm}$ - placed in front of it, was used as a light source. The results are represented in Table II.

TABLE II

RELATIVE PHOTOCHEMICAI ACTIVITY OF DISINTEGRATED GRANA SUSPENSIONS AT LOW AND HIGH LIGHT INTENSITIES

\begin{tabular}{|c|c|c|}
\hline $\begin{array}{l}\text { Light intensity in } \\
\qquad \mathrm{rgs} / \mathrm{cm}^{2} / \mathrm{sec}\end{array}$ & $1.70 \cdot 10^{8}$ & $2.07 \cdot 70^{8}$ \\
\hline Photochemical activity & $\mathbf{o}$ & 38 \\
\hline of vibrated grana sus- & 15 & 37 \\
\hline pensions in per cents & I5 & 46 \\
\hline of that of the controls & 21 & 85 \\
\hline
\end{tabular}

* Inaccurate value

If particles of the critical volume were totally inactivated by removing part of their chlorophyll the activity percentages must remain unchanged in strong light. Since only the number of active particles is decreased, the HIII reaction of the vibrated suspension will become saturated at the same light intensity as that, at which the control shows saturation. 
However, if the particle activity is only reduced by a partial loss of chlorophyll the saturation of the vibrated suspension is shifted to higher intensities. This means that the activity percentage will increase with increasing light intensity. It is obvious from Table II that a marked rise of the relative photochemical activity in strong light occurs.

So we conclude that, at least part of the fragments are not inactivated by a partial loss of their chlorophyll molecules.

\section{DISCUSSION}

From the flashing light experiments on the photosynthesis of Chlovella, originally carried out by EMERSON AND ARNOLD ${ }^{1}$, as well as from those done by CIENDENNING AND Ehrmantraut 19 on the photochemical reduction of both carbon dioxide and quinone, it follows that an enzyme, present in a small amount as compared with the chlorophyll concentration, limits the dark reaction. The equality of the periods needed for the completion of the limiting dark reaction in both photosynthesis and quinone reduction strongly suggests that the same enzyme is active in both processes.

EMERSON AND ARNoLD' ${ }^{1}$ demonstrated that at flash saturation of photosynthesis one carbon dioxide molecule is reduced per 2500 chlorophyll molecules present. If we assume that the above-mentioned limiting enzyme is able to allow the reduction of one carbon dioxide molecule during its working period, it follows that this enzyme occurs in a concentration $\mathbf{I} / \mathbf{2 5 0 0}$ of that of chlorophyll.

If we furthermore assume that the carbon dioxide reduction as measured by EMERSON AND ARNOLD ${ }^{1}$ is a ten-quanta reaction, it means that the absorption of ten quanta is required for blocking the enzyme.

However, it follows from the results of CLENDENNING AND EHRMANTRAuT ${ }^{10}$ that this enzyme is not directly involved in carbon dioxide reduction. This makes it rather improbable that the blocking is the result of a ten-quanta reaction. So, let it be a $n$-quanta reaction. Consequently, the number $(N)$ of chlorophyll molecules, present per one enzyme molecule amounts to

$$
N=n / 10 \cdot 2500 \text {. }
$$

The value of $n$ may be derived from our results by the following reasoning.

If such an enzyme occurs in a small amount as compared with that of the chlorophyll, it must be expected that, when decreasing the size of grana fragments below a critical volume, chlorophyll molecules able to receive quanta to the benefit of the photochemical reactions are removed. From such a withdrawal a decline of the photochemical rate must result. This phenomenon was actually demonstrated to occur in our experiments. The critical volume proved to amount to about $10^{6} \mathrm{~A}^{3}$.

When accepting with RABINOwITCH ${ }^{20}$ that chlorophyll occurs in the grana in the mean concentration of 0.06 to $0.2 M$ - the computation of these figures was based on data of various authors - and assuming that this mean concentration does not appreciably deviate from the real one, it follows that particles of the critical size contain 40 to I20 chlorophyll molecules. This means that these numbers indicate the order of magnitude of the amount of chlorophyll molecules cooperating with one enzyme molecule in intact chloroplasts. In other words the amount of chlorophyll molecules. present per enzyme molecule numbers about roo.

References p. 240 . 
Consequently the number $(n)$ of quanta required for the blocking of this enzyme can be computed from equation (I) by substituting Ioo for $N$. So $n$ amounts to about $1 / 2$. However, since the quantities used for the calculation of $n$ are approximations, we only may state that the value of $n$ is in the order of magnitude of unity. This indicates that the process in which this enzyme acts in photosynthesis is a one-quantum reaction.

A few words may be said with regard to the occurrence of a photosynthetic unit. Apart from various reasons discussed by FRANK AND HERzFELD ${ }^{21}$-and also FrancK ${ }^{22}$ - the above results indicate that the conception of a unit of about rooo chlorophyll molecules as proposed by GAFFRON AND WOHL ${ }^{23}$ and by WOHL ${ }^{24}$ does not hold. They interpreted the results of EMERSON AND ARNOLD ${ }^{1}$ in a much more detailed way than the latter authors did themselves.

In discussing the ratio: molecules carbon dioxide reduced per flash/chlorophyll molecules present, EMERSON ${ }^{25}$ suggested that a substance in small amount as compared with the chlorophyll concentration may interfere in the photochemical process in such a way, that its activity determines the ratio in question.

FRANCK and co-workers argued in favour of the existence of an enzyme which stabilises unstable intermediates in the photochemical reaction chain. This enzyme is considered to be present in a small amount too. These authors reject any hypothesis concerning the existence of a photosynthetic unit.

The experiments of Clendenning and Ehrmantraut ${ }^{19}$ indicate that such an enzyme acts in the reduction of both carbon dioxide and quinone.

The results of our experiments point to the occurrence of one enzyme molecule per about Ioo chlorophyll molecules. Formally, a such-like combination may be called a photosynthetic unit. In this sense even FrancK's conception answers the definition of a unit. Since, however, this kind of definition does not indicate the slightest evidence either of some definite structure or of the way in which the chlorophyll molecules correspond with an active centre, we prefer to refrain from the use of the term "unit".

\section{SUMMARY}

I. The relation between the size of fragments of disintegrated spinach grana and their photochemical activity in the HIIL reaction was investigated.

2. Reduction of the fragment size below $10^{6} \mathrm{~A}^{3}$ caused a pronounced decrease of the photochemical activity. Particles of this "critical" volume presumably contain 40 to 120 chlorophyll molecules.

3. The inactivation of these particles by reduction of their volume proceeds gradually.

4. It was argued that the conception of the photosynthetic unit seems to be inopportune at the present; the evidence obtained up to now only indicates the occurrence of a rate limiting enzyme in a quantity small compared with that of the chlorophyll.

5. The data presented seem to indicate that the process in which this enzyme is involved in photosynthesis is linked to a one-quantum reaction.

\section{RÉSUMÉ}

I. Nous avons étudié le rapport entre la dimension des particules des grains des chloroplastes amoindrites d'épinards et leur activité photochimique dans la réaction d'après HiLl.

2. Diminution de la dimension des particules au-dessous de ${ }^{6} 0^{6} \mathrm{~A}^{3}$ causait un déclin prononcé de l'activité photochimique. Particules de cette dimension contiennent probablement $40-120$ molecules de chlorophylle. ment.

3. L'inactivation des particules, causée par la diminution de leur dimensions procède graduelle- 
4. Nous avons discuté que la conception de l'unité de photosynthèse est sans signification actuellement; jusqu'alors les expériments ont indiqué seulement la présence d'une enzyme limitante la réaction photosynthétique et qui se trouve en concentration très basse comparée à celle de la chlorophylle.

5. Nos résultats rendent probable que la réaction, dans laquelle cette enzyme fonctionne en photosynthèse, est basée sur l'absorption d'un seul quantum.

\section{ZUSAMMENFASSUNG}

I. Die Beziehung zwischen der Grösse der Teilchen zerkleinerter Spinatgranen und ihrer photochemischen Aktivitat wurde untersucht.

2. Reduktion der Teilchengrösse unterhalb ${ }^{6} \mathrm{~A}^{6} \mathrm{~A}^{3}$ verursachte eine deutliche Herabsetzung der photochemischen Aktivität. Teilchen von dieser Grösse enthalten wahrscheinlich $40-120$ Chlorophyllmolekülen.

3. Die Inaktivierung dieser Teilchen durch Zerkleinerung verläuft allmählich.

4. Es wurde argumentiert dass der Begriff einer Photosynthese-einheit momentan nicht opportun sei, da die Versuche nur auf eine quantitative Relation zwischen ein Ferment, das die Photosynthese limitiert, und das Chlorophyll hindeuten.

5. Die Ergebnisse deuten darauf hin, dass der photosynthetische Prozess, an welchem dieses Ferment beteiligt ist, nur eines Quantum erfordert.

\section{REFERENCES}

1 R. Emerson and W. Arnold, J. Gen. Physiol., i6 (1932) Igr.

W. Arnold and H. I. Kohn, $J$. Gen. Physiol., i 8 (r934) 109.

3 R. Emerson, L. Green and J. L. Webb, Plant Physiol., r 5 (I940) 311.

W. Vishniac AND S. OChOA, Nature, I67 (I95I) 768.

5 L. J. Tolmach, Nature, I67 (I95I) 946.

6 L. J. Tolmach, Arch. Biochem. Biophys., 33 (I95I) 120.

7 F. C. Gerretsen, Plant and Soil, 3 (195I) I.

8 C. S. French, Ann. Rev. Biochem., I5 (I946) 397.

A. S. Holt AND C. S. French, Photosynthesis in Plants, (1949) 277. Iowa State Coll. Press Ames.

$10 \mathrm{H}$. Gafyron and E. W. FAGER, Ann. Rev. Plant Physiol., 2 (I95I) 87.

$11 \mathrm{R}$. Hill, Advances in Enzymol., 12 (195I) $\mathrm{I}$.

$12 \mathrm{O}$. WARBURG AND W. LÜTTGENS, Schwermetalle als Wirkungsgruppen von Fermenten (1948) 170, Saenger, Berlin.

$13 \mathrm{~B}$. KOK, personal communication.

14 P. R. Gorham and K. A. Clendenning, Can. J. Research, 28 (1950) 5 I3.

15 R. O. Prudhomme and P. Grabar, J. Chim. Phys., 46 (1949) 323.

16 A. Dognon And Y. Simondt, J. Chim. Phys., 46 (1949) 396.

17 R. O. Prudhomme, J. Chim. Phys., 46 (1949) 318.

18 H. W. Milner, N. S. LAWRHNCE AND C. S. French, Science, II I (1950) 633.

19 K. A. Clendenning and H. C. Ehrmantraut, Arch. Biochem., 29 (I950) 387

20 E. I. Rabinowitch, Photosynthesis $I$, Intersci. Publ. Inc., New York (1945) $4^{12 .}$

21 J. Franck and K. F. Herzfeld, J. Phys. Chem., 45 (r94 I) 978.

22 J. Franck, Ann. Rev. Plant Physiol., 2 (I95I) 53.

$23 \mathrm{H}$. GaFfron AND K. WOHL, Naturwissenschaften, 24 (1936) $8 \mathrm{r}$.

24 K. WoHL, $Z$. phys. Chem., B 37 (1937) 105; 122; 186; 209.

26 R. Emerson, Ergebn. Enzymforsch., 5 (1936) 303. 